\title{
The potential of domestic production and imports of oil and gas in China: an energy return on investment perspective
}

\author{
Zhao-Yang Kong ${ }^{1} \cdot$ Xiu-Cheng Dong ${ }^{1} \cdot$ Qian Shao $^{2} \cdot$ \\ Xin $\mathrm{Wan}^{3} \cdot$ Da-Lin Tang ${ }^{4} \cdot$ Gui-Xian Liu ${ }^{1}$
}

Received: 7 March 2016/Published online: 1 October 2016

(c) The Author(s) 2016. This article is published with open access at Springerlink.com

\begin{abstract}
Concerns about China's energy security have escalated because of the country's high dependency on oil and gas imports, so it is necessary to calculate the availability of domestic oil and gas resources and China's ability to obtain foreign energy through trade. In this work, the calculation was done by using the energy return on investment (EROI) method. The results showed that the EROI $_{\text {stnd }}$ (i.e., standard EROI) of China's oil and gas extraction decreased from approximately 17.3:1 in 1986 to 8.4:1 in 2003, but it increased to $12.2: 1$ in 2013. From a

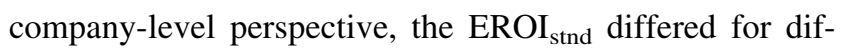
ferent companies and was in the range of $(8-12): 1$. The $\mathrm{EROI}_{2, \mathrm{~d}}$ (EROI considering energy outputs after processed and direct energy inputs) for different companies was in the range of (3-7):1. The EROI of imported oil (EROI IO) declined from 14.8:1 in 1998 to approximately 4.8:1 in 2014 , and the EROI of imported natural gas $\left(\mathrm{EROI}_{\mathrm{ING}}\right)$ declined from 16.7:1 in 2009 to 8.6:1 in 2014. In 2015, the EROI $_{I O}$ and EROI ING showed a slight increase due to decreasing import prices. In general, this paper suggests that from a net energy perspective, it has become more difficult for China to obtain oil and gas from both domestic
\end{abstract}

Xiu-Cheng Dong

dongxiucheng@cup.edu.cn

1 School of Business Administration, China University of Petroleum (Beijing), Beijing 102249, China

2 School of Business, Tianjin University of Finance and Economics, Tianjin 300222, China

3 Tangshan Iron and Steel Group Co., Ltd, Tangshan 261000, China

4 China Petroleum Enterprise Association, Beijing 100724, China

Edited by Xiu-Qin Zhu production and imports. China is experiencing an EROI decline, which demonstrates the risk in the use of unsustainable fossil resources.

Keywords EROI - Oil and gas extraction - Imported oil · Imported natural gas · China

\section{Introduction}

Few issues, if any, are as fundamentally important to industrial societies and their economies as the future oil and gas supplies (Cleveland 2005; Gagnon et al. 2009). Oil and gas provide nearly $60 \%$ of the world's energy (BP 2014). Global food production and most economies rely heavily on oil and gas, and historical restrictions on the availability of oil have had major economic impacts (Munasinghe 2002). China has become the world's largest energy consumer, with consumption increasing from $16.7 \times 10^{12}$ in 1978 to $99.8 \times 10^{12} \mathrm{MJ}$ in 2012 (National Bureau of Statistics of China, 2014; Fan et al. 2015). Together, oil and gas comprise approximately $25.5 \%$ of the consumption of primary energy resources (Safronov and Sokolov 2014). Due to China's limited domestic production capacity, however, increasing amounts of oil and gas have been imported from counties such as Qatar, Indonesia, Malaysia, Russia, and Australia (Kong et al. 2015). Over the last 7 years, China's dependency on imported oil (IO) has increased by $21.5 \%$ annually, and in 2013, it reached 59 percent of total use (Fig. 1). Moreover, China's dependence on imported natural gas (ING) is also rising (Fig. 1) and, according to the BP Energy Outlook 2030, will reach over 40 percent of total use by 2030 (Kong et al. 2015). Thus, oil and gas security has become an issue that cannot be ignored. If an interruption in energy imports 


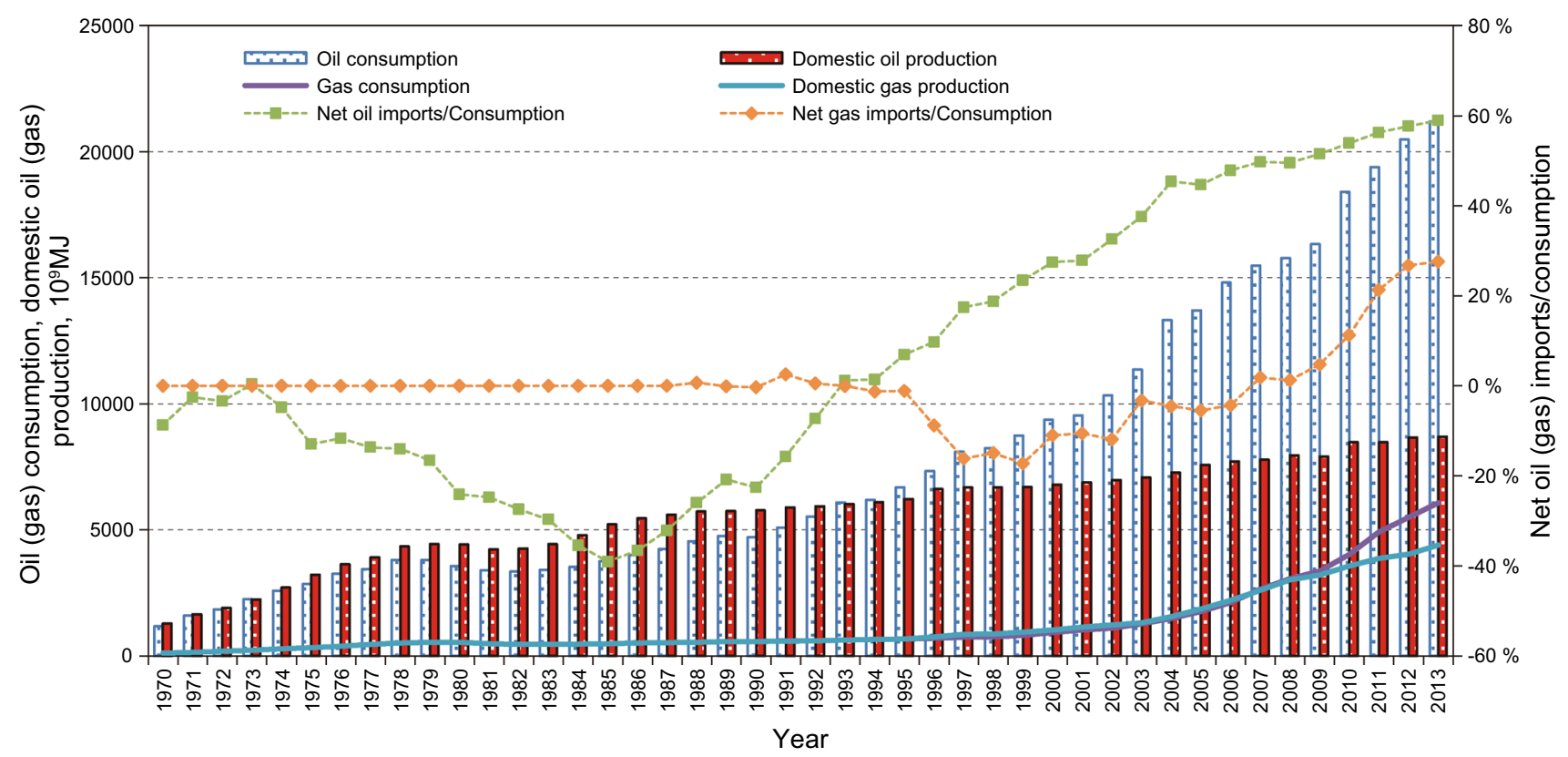

Fig. 1 China's dependence on foreign oil and gas

occurs or the import price increases, China's economy will be seriously affected. For example, as a result of the 1973 oil shock, the world economy endured the hitherto worst recession in postwar history (Kesicki 2010). Therefore, to ensure the country's oil and gas security, it is necessary to calculate the availability of domestic oil and gas resources and China's ability to obtain foreign oil and gas through trade.

The energy return on investment (EROI) is a useful approach for assessing the productive availability of an energy source (Heun and Wit 2012). It is the ratio of energy that is produced by a process to the energy that is consumed in carrying out that process (Gagnon et al. 2009). If the EROI of a fuel is high, then only a small fraction of the energy produced is required to maintain production, and the majority of that produced energy can be used to run the general economy. In contrast, if the EROI is very low, the majority of the energy produced must be used to ensure continued energy production, and very little net energy is available for useful economic work. Thus, high EROI fuels are vital to economic growth and productivity (Gagnon et al. 2009).

Unfortunately, the peer-reviewed literature in this field has paid only minimal attention to the EROI of oil and gas extraction (OGE) in China. To the best of our knowledge, only three papers have examined the EROI of OGE in China. In 2011, Hu et al. (2011) derived an EROI of the Daqing oil field, the largest oil field in China. They estimated that its EROI was 10:1 in 2001 but declined to 6.5:1 in 2009. In 2013, Hu et al. (2013) found that the EROI for China's OGE fluctuated from 12:1 to 14:1 in the mid-1990s and declined to 10:1 during the period of 2007-2010. In 2014, Xu et al. (2014) forecasted that the Daqing oil field's EROI would continuously decline from 7.3:1 to 4.7:1.

In this paper, we address the EROI of OGE in China not only from an industry-level perspective, but also from a company-level perspective. An analysis of the EROI of oil companies could provide some information about energy inputs and thus serve as a reference for policymakers and investors. Besides, we prefer to analyze EROI not only at the mine mouth (the conventional approach) but also at the refinery, because crude oil cannot be directly used by cars and needs be processed. Of course, oil processing consumes energy, which should also be considered in energy inputs.

Lambert et al. (2014) studied the EROI of imported oil $\left(\mathrm{EROI}_{\mathrm{IO}}\right)$ for 12 developing countries, including China. They have found that most developing nations have EROI values below 8-10. As a large gas importer, it is necessary to estimate the EROI of imported natural gas $\left(\mathrm{EROI}_{\mathrm{ING}}\right)$ of China. Through this study, we aimed to answer four questions:

(1) What is the EROI of China' oil and gas extraction in 1985-2012?

(2) What are the EROI values of China's four oil companies: CNPC (China National Petroleum Corporation), Sinopec (Sinopec Group), CNOOC (China National Offshore Oil Corporation), and Yanchang (Shanxi Yanchang Petroleum (Group) Co., Ltd.)?

(3) Are the EROI values of these four oil companies lower or higher than the national average value?

(4) What are the EROI IO and EROI ${ }_{\text {ING }}$ values of China? 


\section{EROI methodology and data for China's domestic production of oil and gas}

\subsection{EROI methodology for domestic production of oil and gas}

EROI can broadly be described as the ratio of the energy made available to society through a certain process and the energy cost to implement this process (Cleveland and O'Connor 2011; Lundin 2013). The general equation for EROI is given in Eq. (1):

EROI $=\frac{\text { Energy produced (outputs) }}{\text { Energy consumed (inputs) }}$

The numerator is the sum of all energy produced in a given timeframe, and the denominator is the sum of the energy costs. EROI is typically calculated without discounting for time. Because the numerator and denominator are usually assessed in the same units, the ratio derived is dimensionless and often expressed as EROI: 1 in text (Lundin 2013), e.g., 10:1. This implies that a particular process yields 10 joules on an investment of $1 \mathrm{~J}$.

Some previous EROI analyses have generated a wide variety of results, including apparently conflicting results, when applied to the same energy resource. The reasons for these differences are not limited to intrinsic variations in energy resource quality, extraction technology, and varying geology but also include methodological issues including different boundaries of analysis, different methods used to estimate indirect energy inputs, and issues related to energy quality (Hu et al. 2013).

In order to formalize the analysis of EROI, Mulder and Hagens (2008) established a consistent theoretical framework for EROI analysis that encompasses the various methodologies. Murphy et al. (2011) propose a more explicit two-dimensional framework for EROI analysis that describes three boundaries for energy analysis and five levels of energy inputs, as shown in Table 1.
In Table 1, the numbers " 1, " " 2 ," and " 3 " describe the boundary for energy outputs, i.e., where the analysis is terminated (mine mouths, refinery or point of use), while the "d," "i," "aux," "lab," or "env" in subscript refer to the abbreviations for different types of inputs considered: They are direct energy (d) used on site, indirect energy (i) used to purchase material inputs constructed offsite such as steel for sand pipes, embodied energy in the wages of labor (lab), energy afforded by governmental services in the public sector (aux), and energy embodied in environmental costs for assessment (env), respectively.

Because most EROI analyses account for both direct and indirect energy and material inputs, but not for labor or environmental costs, Murphy et al. (2011) deem this boundary to be the standard EROI and assign it the name EROI $_{\text {stnd. }}$. Using the standard calculation, we have the following equation:

$\mathrm{EROI}_{\text {stnd }}=\frac{E_{O}}{E_{d}+E_{i}}$

where $E_{o}$ is all energy outputs, $\mathrm{J} ; E_{d}$, and $E_{i}$ represent the total input and direct input, $\mathrm{J}$, respectively, of different types of energy. The challenge is that the indirect energy inputs are rarely available as physical energy units. Rather, the data are available in monetary units as, e.g., investments in industrial equipment. Thus, Eq. 3 is used to complete the EROI analysis:

$\mathrm{EROI}_{\text {stnd }}=\frac{E_{O}}{E_{d}+M_{i} \times E_{\text {ins }}}$

where $M_{i}$ represents the indirect inputs in monetary terms and $E_{\text {ins }}$ expresses the energy intensity of a dollar input for indirect components.

Other approaches (e.g., including environmental) can be conducted as sensitivity analyses, which will examine how changing variables affect the outcome. If both environmental and indirect costs are considered, the EROI can be expressed as EROI $_{1, \mathrm{i}+\text { env }}$. The critical point is to clarify what is included in the analysis (Murphy et al. 2011).
Table 1 Two-dimensional framework for EROI analysis

\begin{tabular}{llll}
\hline Levels for energy inputs & \multicolumn{2}{l}{ Boundary for energy outputs } \\
\cline { 2 - 4 } & 1. Extraction & 2. Processing & 3. End-use \\
\hline Direct energy and material inputs & $\mathrm{EROI}_{1, \mathrm{~d}}$ & $\mathrm{EROI}_{2, \mathrm{~d}}$ & $\mathrm{EROI}_{3, \mathrm{~d}}$ \\
Indirect energy and material inputs & $\mathrm{EROI}_{\text {stnd }}$ & $\mathrm{EROI}_{2, \mathrm{i}}$ & $\mathrm{EROI}_{3, \mathrm{i}}$ \\
Indirect labor consumption & $\mathrm{EROI}_{1, \mathrm{lab}}$ & $\mathrm{EROI}_{2, \mathrm{lab}}$ & $\mathrm{EROI}_{3, \text { lab }}$ \\
Auxiliary services consumption & $\mathrm{EROI}_{1, \text { aux }}$ & $\mathrm{EROI}_{2, \text { aux }}$ & $\mathrm{EROI}_{3, \text { aux }}$ \\
Environmental & $\mathrm{EROI}_{1, \mathrm{env}}$ & $\mathrm{EROI}_{2, \mathrm{env}}$ & $\mathrm{EROI}_{3, \text { env }}$ \\
\hline
\end{tabular}




\subsection{China's oil and gas extraction data}

\subsubsection{Energy outputs}

The National Bureau of Statistics of China provides data on energy outputs and energy inputs for OGE (Table 2) (National Bureau of Statistics of China 2014). Open access data are available from 1985 onward, so we calculated the EROI $_{\text {OGC }}$ from 1985 to 2012. This output was converted to heat units using the values in Table 3 . Thus, we can obtain energy output as heat equivalents (Fig. 2).

\subsubsection{Energy inputs}

Direct energy inputs to the OGE sector mainly include raw coal, crude oil, gasoline, diesel oil, fuel oil, natural gas, and
Table 3 Conversion factors from physical units to MJ

\begin{tabular}{ll}
\hline & Conversion factor \\
\hline Oil & $41.8, \mathrm{MJ} / \mathrm{kg}$ \\
Natural gas & $38.9, \mathrm{MJ} / \mathrm{m}^{3}$ or $57.18, \mathrm{MJ} / \mathrm{kg}$ \\
Raw coal & $20.9, \mathrm{MJ} / \mathrm{kg}$ \\
Crude oil & $41.8, \mathrm{MJ} / \mathrm{kg}$ \\
Gasoline & $43.1, \mathrm{MJ} / \mathrm{kg}$ \\
Diesel & $42.7, \mathrm{MJ} / \mathrm{kg}$ \\
Fuel oil & $41.8, \mathrm{MJ} / \mathrm{kg}$ \\
Kerosene & $43.1, \mathrm{MJ} / \mathrm{kg}$ \\
Electricity & $3.6, \mathrm{MJ} / \mathrm{kWh}$ \\
Coal equivalent & $29.3, \mathrm{MJ} / \mathrm{kg}$ \\
\hline
\end{tabular}

Table 2 Energy output and energy inputs of OGE in China, in physical units (tce is tonnes of coal equivalent)

\begin{tabular}{|c|c|c|c|c|c|c|c|c|c|c|}
\hline \multirow[t]{2}{*}{ Year } & \multicolumn{2}{|c|}{ Energy output } & \multicolumn{8}{|c|}{ Energy inputs } \\
\hline & $\begin{array}{l}\text { Oil } \\
10^{4} \text {, metric } \\
\text { tons }\end{array}$ & $\begin{array}{l}\text { Gas } \\
10^{8}, \mathrm{~m}^{3}\end{array}$ & $\begin{array}{l}\text { Raw coal } \\
10^{4} \text {, metric } \\
\text { tons }\end{array}$ & $\begin{array}{l}\text { Oil } \\
10^{4} \text {, metric } \\
\text { tons }\end{array}$ & $\begin{array}{l}\text { Gasoline } \\
10^{4} \text {, metric } \\
\text { tons }\end{array}$ & $\begin{array}{l}\text { Diesel } \\
10^{4} \text {, metric } \\
\text { tons }\end{array}$ & $\begin{array}{l}\text { Fuel oil } \\
10^{4} \text {, metric } \\
\text { tons }\end{array}$ & $\begin{array}{l}\text { Gas } \\
10^{8}, \mathrm{~m}^{3}\end{array}$ & $\begin{array}{l}\text { Electricity } \\
10^{8}, \mathrm{kWh}\end{array}$ & $\begin{array}{l}\text { Others } \\
10^{4} \text {, tce }\end{array}$ \\
\hline 1985 & 12,490 & 129 & 92 & 141 & 31 & 28 & 47 & 34 & 85 & 95 \\
\hline 1986 & 13,037 & 134 & 96 & 132 & 27 & 41 & 50 & 34 & 98 & 71 \\
\hline 1987 & 13,392 & 135 & 88 & 120 & 28 & 46 & 79 & 39 & 109 & 62 \\
\hline 1988 & 13,685 & 139 & 105 & 138 & 35 & 50 & 80 & 40 & 123 & 78 \\
\hline 1989 & 13,748 & 145 & 121 & 138 & 36 & 57 & 71 & 39 & 131 & 86 \\
\hline 1990 & 13,831 & 153 & 132 & 141 & 39 & 64 & 130 & 36 & 145 & 92 \\
\hline 1991 & 13,968 & 154 & 117 & 133 & 38 & 64 & 98 & 32 & 158 & 37 \\
\hline 1992 & 14,196 & 157 & 140 & 109 & 42 & 68 & 109 & 40 & 171 & 34 \\
\hline 1993 & 14,400 & 163 & 215 & 141 & 58 & 137 & 157 & 39 & 232 & 75 \\
\hline 1994 & 14,607 & 167 & 229 & 212 & 52 & 142 & 160 & 45 & 240 & 66 \\
\hline 1995 & 15,005 & 180 & 220 & 175 & 59 & 146 & 161 & 42 & 259 & 132 \\
\hline 1996 & 15,729 & 201 & 262 & 174 & 53 & 191 & 105 & 30 & 259 & 61 \\
\hline 1997 & 16,044 & 223 & 310 & 317 & 36 & 157 & 108 & 38 & 315 & 211 \\
\hline 1998 & 16,052 & 223 & 205 & 313 & 33 & 103 & 127 & 35 & 298 & 251 \\
\hline 1999 & 16,000 & 252 & 176 & 331 & 42 & 145 & 144 & 46 & 308 & 325 \\
\hline 2000 & 16,300 & 272 & 186 & 409 & 45 & 162 & 146 & 50 & 322 & 353 \\
\hline 2001 & 16,396 & 303 & 162 & 423 & 44 & 177 & 150 & 58 & 356 & 356 \\
\hline 2002 & 16,700 & 327 & 163 & 448 & 44 & 198 & 142 & 59 & 365 & 369 \\
\hline 2003 & 16,960 & 350 & 186 & 552 & 39 & 168 & 121 & 62 & 357 & 355 \\
\hline 2004 & 17,587 & 415 & 188 & 499 & 37 & 185 & 33 & 49 & 363 & 273 \\
\hline 2005 & 18,135 & 493 & 184 & 504 & 26 & 186 & 26 & 49 & 385 & 269 \\
\hline 2006 & 18,477 & 586 & 187 & 565 & 29 & 187 & 28 & 55 & 316 & 228 \\
\hline 2007 & 18,632 & 692 & 179 & 569 & 31 & 198 & 26 & 64 & 311 & 186 \\
\hline 2008 & 19,044 & 803 & 153 & 696 & 28 & 272 & 37 & 86 & 318 & 180 \\
\hline 2009 & 18,949 & 853 & 155 & 487 & 25 & 230 & 26 & 89 & 333 & 164 \\
\hline 2010 & 20,301 & 949 & 157 & 482 & 24 & 186 & 31 & 102 & 348 & 176 \\
\hline 2011 & 20,288 & 1027 & 151 & 368 & 22 & 192 & 26 & 96 & 375 & 193 \\
\hline 2012 & 20,748 & 1072 & 129 & 463 & 14 & 63 & 12 & 96 & 397 & 153 \\
\hline
\end{tabular}




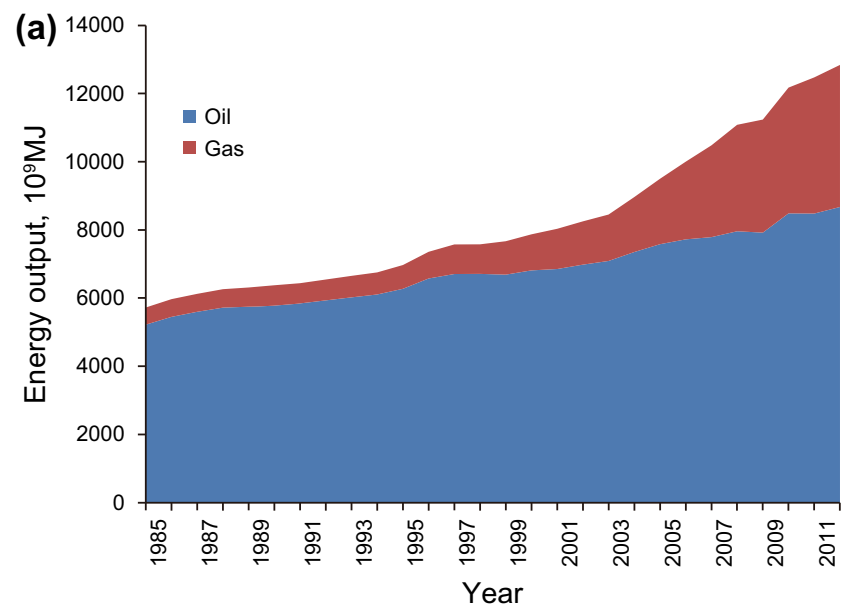

Fig. 2 Energy output and energy inputs for OGE in China

electricity. All of the raw data for direct energy inputs in physical units (Table 2) are also converted into thermal units (Fig. 2) using the conversion factors in Table 3.

We derived indirect energy inputs through multiplying costs by industry energy intensity factors (Table 4), because there is no energy inputs accounting in routine economic data. Indirect monetary costs include the sum of "purchase of equipment and instruments" and "other

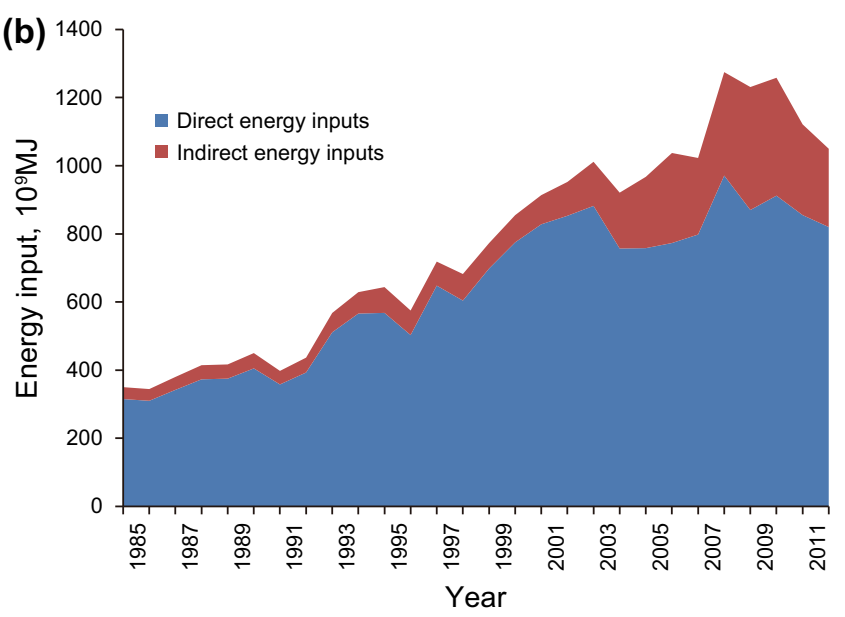

expenses" of "investment" in the China Statistic Yearbook database (National Bureau of Statistics of China 2014). China Statistic Yearbook database did not provide the data about indirect monetary costs before 1995 . The ratio of indirect energy inputs to total energy inputs between 1995 and 2001 fluctuated around $10 \%$, so it was assumed to be $10 \%$ before 1995 . Thus, the indirect energy inputs for OGE can be obtained, as shown in Fig. 2.

Table 4 Indirect energy inputs of oil and natural gas extraction in China

\begin{tabular}{|c|c|c|c|c|c|}
\hline & Raw data, $10^{9}$, yuan & & & Energy intensity for & Indirect energy \\
\hline & $\begin{array}{l}\text { Purchase of equipment } \\
\text { and instruction }\end{array}$ & $\begin{array}{l}\text { Other } \\
\text { expenses }\end{array}$ & Total & & \\
\hline 1995 & 4.5 & 2.2 & 6.7 & 11.3 & 76 \\
\hline 1996 & 5.2 & 2.3 & 7.5 & 9.6 & 72 \\
\hline 1997 & 5.5 & 2.6 & 8.1 & 8.7 & 70 \\
\hline 1998 & 6.1 & 3.2 & 9.3 & 8.4 & 78 \\
\hline 1999 & 6.1 & 3 & 9.1 & 8.2 & 75 \\
\hline 2000 & 6.9 & 3.6 & 10.5 & 7.6 & 80 \\
\hline 2001 & 7.7 & 4.2 & 11.9 & 7.2 & 86 \\
\hline 2002 & 8.6 & 5.6 & 14.2 & 7 & 99 \\
\hline 2003 & 11 & 7.5 & 18.5 & 7 & 130 \\
\hline 2004 & 13.6 & 10.5 & 24.1 & 6.8 & 164 \\
\hline 2005 & 19.8 & 12.9 & 32.7 & 6.4 & 209 \\
\hline 2006 & 25.1 & 19.7 & 44.8 & 5.9 & 264 \\
\hline 2007 & 25.9 & 16.5 & 42.4 & 5.3 & 225 \\
\hline 2008 & 44.4 & 20.2 & 64.6 & 4.7 & 304 \\
\hline 2009 & 55.2 & 21.6 & 76.8 & 4.7 & 361 \\
\hline 2010 & 58.4 & 24 & 82.4 & 4.2 & 346 \\
\hline 2011 & 41.6 & 28.5 & 70.1 & 3.8 & 266 \\
\hline 2012 & 33.3 & 28.8 & 62.1 & 3.7 & 230 \\
\hline 2013 & 39.3 & 27 & 66.3 & 3.5 & 232 \\
\hline
\end{tabular}




\subsection{Oil and gas production data from companies}

\subsubsection{Energy outputs}

The volumes of oil and gas extracted by each company (Table 5) can be easily found in their annual reports (CNPC Annual Reports; Sinopec Annual Reports; CNOOC Annual Reports; Yanchang Social Responsibility Reports). For $\mathrm{EROI}_{\text {stnd, }}$, the energy outputs of each company in Table 6 are equal to the volumes (Table 5) multiplied by the conversion factors.

When calculating the $\mathrm{EROI}_{2, \mathrm{~d}}$ of each company, it is found that the volumes of oil extracted are not equal to the volumes of oil processed, due to the existence of oil imports. To calculate the EROI ${ }_{2, \mathrm{~d}}$ easily, it is assumed the volumes of oil extracted are $4.18 \times 10^{4} \mathrm{MJ}$ per tonne. According to Brandt et al. (2013), the energy losses in the refining process are about $7 \%$. Then, the energy output is $3.89 \times 10^{4} \mathrm{MJ}$ per tonne. We assume the energy output of CNPC, Sinopec, and Yanchang is $3.89 \times 10^{4} \mathrm{MJ}$, then that of CNOOC is $2.14 \times 10^{4} \mathrm{MJ}$, because the yield of light oil products for $\mathrm{CNOOC}$ is lower about $1.75 \times 10^{4} \mathrm{MJ}$ per tonne than that of other companies.

\subsubsection{Energy inputs}

\subsubsection{Energy investment in $O G E$}

\section{(1) Direct energy inputs}

The CNPC's and Yanchang's total direct energy inputs data in Table 7 for the OGE sector are from the CNPC Statistical Yearbooks (CNPC 2014) and the Yanchang Social Responsibility Reports, respectively. The Sinopec Statistical Yearbook provides data on the units of direct energy inputs for OGE (Table 7) (Sinopec 2014). From the volume of oil and gas extracted by Sinopec (Table 5), the total direct energy inputs of Sinopec can be calculated and shown in Table 8.CNOOC's annual reports published only the total direct energy inputs for the whole company without a division by sectors of other activities from 2005 to 2009 (Table 7) (CNOOC Annual Reports). From 2005 to 2008 , the direct energy inputs were mainly consumed by OGE, while part of the direct energy inputs was used in the oil processing sector in 2009, when CNOOC entered the refining business (CNOOC Annual Reports). For CNOOC, we do not have any data on direct energy inputs separated by processing sector for 2009. However, knowing the volume of oil processed by company CNOOC (Table 9) and the specific direct energy inputs required for processing 1 tonne of oil, the amount of total direct energy inputs in the oil processing sector can be calculated. In this paper, it is assumed that the average energy requirement for oil processing by CNOOC equals that needed for the Huizhou Refinery, the largest refinery owned by CNOOC. In $2009,0.28 \times 10^{4} \mathrm{MJ}$ is needed per tonne of oil processed in the Huizhou Refinery (Gong and Wang 2013). Given this amount, the direct energy inputs for the OGE sector can be calculated by subtracting the direct energy inputs for the processing sector from the total direct energy inputs. After obtaining the total direct energy inputs of the four companies (CNPC, Sinopec, SNOOC, Yanchang), they were converted into thermal units (Table 8).

Table 10 shows the direct energy inputs per tonne of oil extraction. These data are required when calculating the EROI $_{2, \mathrm{~d}}$ of each company.

\section{(2) Indirect energy inputs}

Currently, Chinese companies do not provide enough data on indirect monetary costs for oil and gas extraction. To calculate indirect energy inputs, in this work, it is assumed that the ratio of indirect energy inputs to total energy inputs for each company is equal to that for China's oil and gas extraction. For example, the ratio of indirect energy inputs to total energy inputs is $9.4 \%$ in 2001 for China's oil and gas extraction; then, the ratio for CNPC in 2001 is also

Table 5 Amount of oil and gas extracted by each company (oil: $10^{4}$, tonnes; gas: $10^{9}, \mathrm{~m}^{3}$ )

\begin{tabular}{|c|c|c|c|c|c|c|c|c|c|c|c|c|c|}
\hline & 2001 & 2002 & 2003 & 2004 & 2005 & 2006 & 2007 & 2008 & 2009 & 2010 & 2011 & 2012 & 2013 \\
\hline \multicolumn{14}{|l|}{ Oil } \\
\hline CNPC & 11,484 & 11,757 & 11,695 & 12,097 & 12,598 & 13,471 & 13,762 & 13,875 & 13,745 & 14,144 & 14,927 & 15,188 & 15,981 \\
\hline Sinopec & & & & & & 4017 & 4108 & 4180 & 4242 & 4256 & 4273 & 4318 & 4378 \\
\hline CNOCC & & & & & 3197 & 3154 & 3055 & 3244 & 3697 & & & & \\
\hline Yanchang & & & & & & & & & & & 1232 & 1264 & 1263 \\
\hline \multicolumn{14}{|l|}{ Gas } \\
\hline CNPC & 212 & 233 & 263 & 313 & 396 & 480 & 578 & 664 & 738 & 829 & 882 & 935 & 1039 \\
\hline Sinopec & & & & & & 73 & 80 & 83 & 85 & 125 & 146 & 169 & 187 \\
\hline CNOCC & & & & & 70 & 88 & 99 & 105 & 107 & & & & \\
\hline Yanchang & & & & & & & & & & & 0.2 & 2.6 & 4.7 \\
\hline
\end{tabular}


Table 6 Energy output of OGE for each company, in thermal units $\left(10^{9}\right.$, MJ)

\begin{tabular}{|c|c|c|c|c|c|c|c|c|c|c|c|c|c|}
\hline & 2001 & 2002 & 2003 & 2004 & 2005 & 2006 & 2007 & 2008 & 2009 & 2010 & 2011 & 2012 & 2013 \\
\hline \multicolumn{14}{|l|}{ Oil } \\
\hline CNPC & 4800 & 4914 & 4889 & 5057 & 5266 & 5631 & 5753 & 5800 & 5745 & 5912 & 6239 & 6349 & 6680 \\
\hline Sinopec & & & & & & 1679 & 1717 & 1747 & 1773 & 1779 & 1786 & 1805 & 1830 \\
\hline CNOCC & & & & & 1336 & 1318 & 1277 & 1356 & 1545 & & & & \\
\hline Yanchang & & & & & & & & & & & 515 & 528 & 528 \\
\hline \multicolumn{14}{|l|}{ Gas } \\
\hline CNPC & 825 & 906 & 1023 & 1218 & 1540 & 1867 & 2248 & 2583 & 2871 & 3225 & 3431 & 3637 & 4042 \\
\hline Sinopec & & & & & & 284 & 311 & 323 & 331 & 486 & 568 & 657 & 727 \\
\hline CNOCC & & & & & 272 & 342 & 385 & 408 & 416 & & & & \\
\hline Yanchang & & & & & & & & & & & 1 & 10 & 18 \\
\hline
\end{tabular}

Table 7 Total direct energy inputs for OGE for each company $\left(10^{4}\right.$, tce $)$

\begin{tabular}{|c|c|c|c|c|c|c|c|c|c|c|c|c|c|}
\hline & 2001 & 2002 & 2003 & 2004 & 2005 & 2006 & 2007 & 2008 & 2009 & 2010 & 2011 & 2012 & 2013 \\
\hline CNPC & 1840 & 1851 & 1905 & 1960 & 2106 & 2191 & 2410 & 2443 & 2467 & 2492 & 2517 & 2542 & 2568 \\
\hline Sinopec $^{\mathrm{a}}$ & & & & & & 111.7 & 104.9 & 105.1 & 102.4 & 100.4 & 105.9 & 105.9 & 105.3 \\
\hline $\mathrm{CNOCC}^{\mathrm{b}}$ & & & & & 391 & 413 & 480 & 581 & 746 & & & & \\
\hline Yanchang & & & & & & & & & & & 147.8 & 146.6 & 145 \\
\hline
\end{tabular}

a Sinopec's units of direct energy inputs for OGE are kgce/t

b The 2009 data for CNOOC refer to the total direct inputs for OGE and oil processing

Table 8 Total direct energy inputs of OGE for each company, in thermal units $\left(10^{9}, \mathrm{MJ}\right)$

\begin{tabular}{|c|c|c|c|c|c|c|c|c|c|c|c|c|c|}
\hline & 2001 & 2002 & 2003 & 2004 & 2005 & 2006 & 2007 & 2008 & 2009 & 2010 & 2011 & 2012 & 2013 \\
\hline CNPC & 539.1 & 542.3 & 558.2 & 574.3 & 617.1 & 642.0 & 706.1 & 715.8 & 722.8 & 730.2 & 737.5 & 744.8 & 752.4 \\
\hline Sinopec & & & & & & 153.5 & 149.1 & 152.7 & 150.9 & 159.4 & 174.9 & 182.8 & 188.7 \\
\hline CNOOC & & & & & 114.6 & 113.1 & 119.3 & 123.9 & 140.1 & & & & \\
\hline Yanchang & & & & & & & & & & & 43.4 & 43.1 & 42.5 \\
\hline
\end{tabular}

Table 9 Amount of oil processed $\left(10^{4}\right.$, tonnes)

\begin{tabular}{|c|c|c|c|c|c|c|c|c|c|c|c|c|c|}
\hline & 2001 & 2002 & 2003 & 2004 & 2005 & 2006 & 2007 & 2008 & 2009 & 2010 & 2011 & 2012 & 2013 \\
\hline CNPC & 8795 & 8947 & 9255 & 10,370 & 11,061 & 11,587 & 12,173 & 12,530 & 12,512 & 13,529 & 14,484 & 14,716 & 14,602 \\
\hline Sinopec & & & & & & 15,651 & 16,576 & 17,294 & 18,824 & 21,297 & 21,892 & 22,309 & 23,370 \\
\hline CNOCC & & & & & & & & & 2081 & & & & \\
\hline Yanchang & & & & & & & & & & & 1302 & 1400 & 1405 \\
\hline
\end{tabular}

$9.4 \%$. The direct energy inputs for CNPC in 2001 is $539.1 \times 10^{9} \mathrm{MJ}$; then, the indirect energy inputs is $56 \times 10^{9} \mathrm{MJ}$. Indirect energy inputs of each company are in Table 11.
2.3.2.2 Energy investment in oil transportation Oil companies do not provide an explicit accounting of energy consumption during the process of oil transportation. Oil transportation relies on pipelines in China, and the average 
Table 10 Direct energy inputs per tonne of oil extraction, in thermal units $\left(10^{4}, \mathrm{MJ}\right)$

\begin{tabular}{lccccccccccccc}
\hline & 2001 & 2002 & 2003 & 2004 & 2005 & 2006 & 2007 & 2008 & 2009 & 2010 & 2011 & 2012 & 2013 \\
\hline CNPC & 0.40 & 0.39 & 0.39 & 0.38 & 0.38 & 0.36 & 0.35 & 0.37 & 0.35 & 0.33 & 0.32 & 0.31 & 0.29 \\
Sinopec & & & & & & 0.33 & 0.31 & 0.31 & 0.30 & 0.29 & 0.31 & 0.31 & 0.31 \\
CNOOC & & & & & 0.30 & 0.28 & 0.30 & 0.29 & 0.30 & & & & \\
Yanchang & & & & & & & & & & & 0.35 & 0.33 & 0.33 \\
\hline
\end{tabular}

\begin{tabular}{llllllrrrrrrrr}
\hline & 2001 & 2002 & 2003 & 2004 & 2005 & 2006 & 2007 & 2008 & 2009 & 2010 & 2011 & 2012 & 2013 \\
\hline CNPC & 56 & 63 & 82 & 124 & 170 & 220 & 199 & 224 & 300 & 277 & 230 & 209 & 211 \\
Sinopec & & & & & & 52 & 42 & 48 & 63 & 60 & 54 & 51 & 53 \\
CNOOC & & & & & 32 & 39 & 34 & 39 & 58 & & & & \\
Yanchang & & & & & & & & & & & 14 & 12 & 12 \\
\hline
\end{tabular}

\begin{tabular}{lll}
\hline & Energy intensity, MJ/tonne-km & Fuel mix and their percentage \\
\hline Sea tanker & 0.023 & Residual oil $(100 \%)$ \\
Pipeline: oil & 0.3 & Residual oil $(50 \%)$ and electricity $(50 \%)$ \\
Pipeline: NG & 0.372 & NG $(99 \%)$ and electricity $(1 \%)$ \\
\hline
\end{tabular}

Table 11 Indirect energy inputs of each company $\left(10^{9}\right.$, $\mathrm{MJ})$

Table 12 Energy intensity and fuel mix for each transportation mode produce that material (Hall et al. 2009). In 1986, Kaufmann (1986) derived an explicit method to quantitatively assess the $\mathrm{EROI}_{\mathrm{IO}}$ (Eq. 4). Because such financial data are usually available, the $\mathrm{EROI}_{\mathrm{IO}}$ can be derived with a moderate degree of accuracy (Lambert et al. 2014). In 2010, King (2010) developed a metric called the energy intensity ratio (EIR), which is similar to Kaufmann's EROI ${ }_{\mathrm{IO}}$, and calculated it for various industrial fuels in the US over time. His study suggested that the EIR is an easily calculated and effective proxy for the EROI for individual fuels.

$\mathrm{EROI}_{\mathrm{IO}}=\frac{E_{\mathrm{IO}}}{E_{\mathrm{p}, \mathrm{OIL}}}=\frac{E_{\mathrm{OIL}} \times M_{\mathrm{IO}}}{E I_{\mathrm{GDP}} \times P_{\mathrm{OIL}} \times M_{\mathrm{IO}}}$

where, $E_{\mathrm{OIL}}$ is the unit energy content of oil, $P_{\mathrm{OIL}}$ is the price of total oil imported, $M_{\mathrm{IO}}$ is the amount of oil purchased, $E I_{\mathrm{GDP}}$ is the economic intensity of the economy, $E_{\mathrm{IO}}$ is the total energy content of the oil purchased, and $E_{\mathrm{p}, \text { OIL }}$ is the total energy inputs in the purchasing phase. Usually, IO includes two phases: purchasing and international transportation (Fig. 3). Equation (4) only considers the purchasing phase,

Similar to the EROI ${ }_{I O}$ equation, the EROI ING can be nomic activity. The ability to purchase critically required energy depends upon what else the economy can generate to sell it to the world, as well as the fuel required to grow or energy inputs of CNPC, Sinopec, and CNOOC for processing per tonne of oil in Table 13 are from literature (CNPC 2014; Sinopec 2014; Gong and Wang 2013). For Yanchang, the total direct energy inputs for oil processing MJ, respectively (Yanchang Social Responsibility cessing per tonne of oil (Table 13) is equal to its total direct energy inputs for oil processing divided by the amount of oil processed (Table 9). Table 14 shows the to sell it the world, as well as the fuel required to grow or while both phases are considered in this paper (Eq. 5).

$\mathrm{EROI}_{\mathrm{IO}}=\frac{E_{\mathrm{IO}}}{E_{\mathrm{p}, \mathrm{OIL}}+E_{\mathrm{t}, \mathrm{OIL}}}$

where $E_{\mathrm{t}, \mathrm{OIL}}$ refers to the total energy inputs in the international transportation phase. calculated as follows:

$\mathrm{EROI}_{\mathrm{ING}}=\frac{E_{\mathrm{ING}}}{E_{\mathrm{p}, \mathrm{NG}}+E_{\mathrm{t}, \mathrm{NG}}}$

An economy without enough domestic fossil fuel must import fuel and pay for it with some type of surplus eco-

\section{EROI methodology and data for imports of oil and gas}

\subsection{EROI methodology for imported oil (IO) and imported natural gas (ING)}

$$
\mathrm{EROI}_{\mathrm{ING}}=\overline{E_{\mathrm{p}, \mathrm{NG}}+E_{\mathrm{t}, \mathrm{NG}}}
$$


Table 13 Direct energy inputs for processing per tonne of oil, in physical units

\begin{tabular}{|c|c|c|c|c|c|c|c|c|c|c|c|c|c|}
\hline & 2001 & 2002 & 2003 & 2004 & 2005 & 2006 & 2007 & 2008 & 2009 & 2010 & 2011 & 2012 & 2013 \\
\hline CNPC, kgoe & 86.4 & 89.3 & 83.4 & 78.7 & 80.6 & 78.0 & 75.6 & 71.6 & 67.6 & 65.5 & 65.0 & 64.1 & 64.0 \\
\hline Sinopec, kgoe & & & & & & 66.9 & 65.9 & 63.8 & 61.3 & 58.2 & 57.0 & 56.2 & 57.5 \\
\hline CNOCC, kgoe & & & & & & & & & 63.9 & & & & \\
\hline Yanchang, kgce & & & & & & & & & & & 157.7 & 143.9 & 139.5 \\
\hline
\end{tabular}

Table 14 Direct energy inputs for processing per tonne of oil, in thermal units $\left(10^{4}, \mathrm{MJ}\right)$

\begin{tabular}{llllllllllllll}
\hline & 2001 & 2002 & 2003 & 2004 & 2005 & 2006 & 2007 & 2008 & 2009 & 2010 & 2011 & 2012 & 2013 \\
\hline CNPC & 0.36 & 0.37 & 0.35 & 0.33 & 0.34 & 0.33 & 0.32 & 0.30 & 0.28 & 0.27 & 0.27 & 0.27 & 0.27 \\
Sinopec & & & & & & 0.28 & 0.28 & 0.27 & 0.26 & 0.24 & 0.24 & 0.24 & 0.24 \\
CNOCC & & & & & & & & & 0.28 & & & & \\
Yanchang & & & & & & & & & & & 0.46 & 0.42 & 0.41 \\
\hline
\end{tabular}

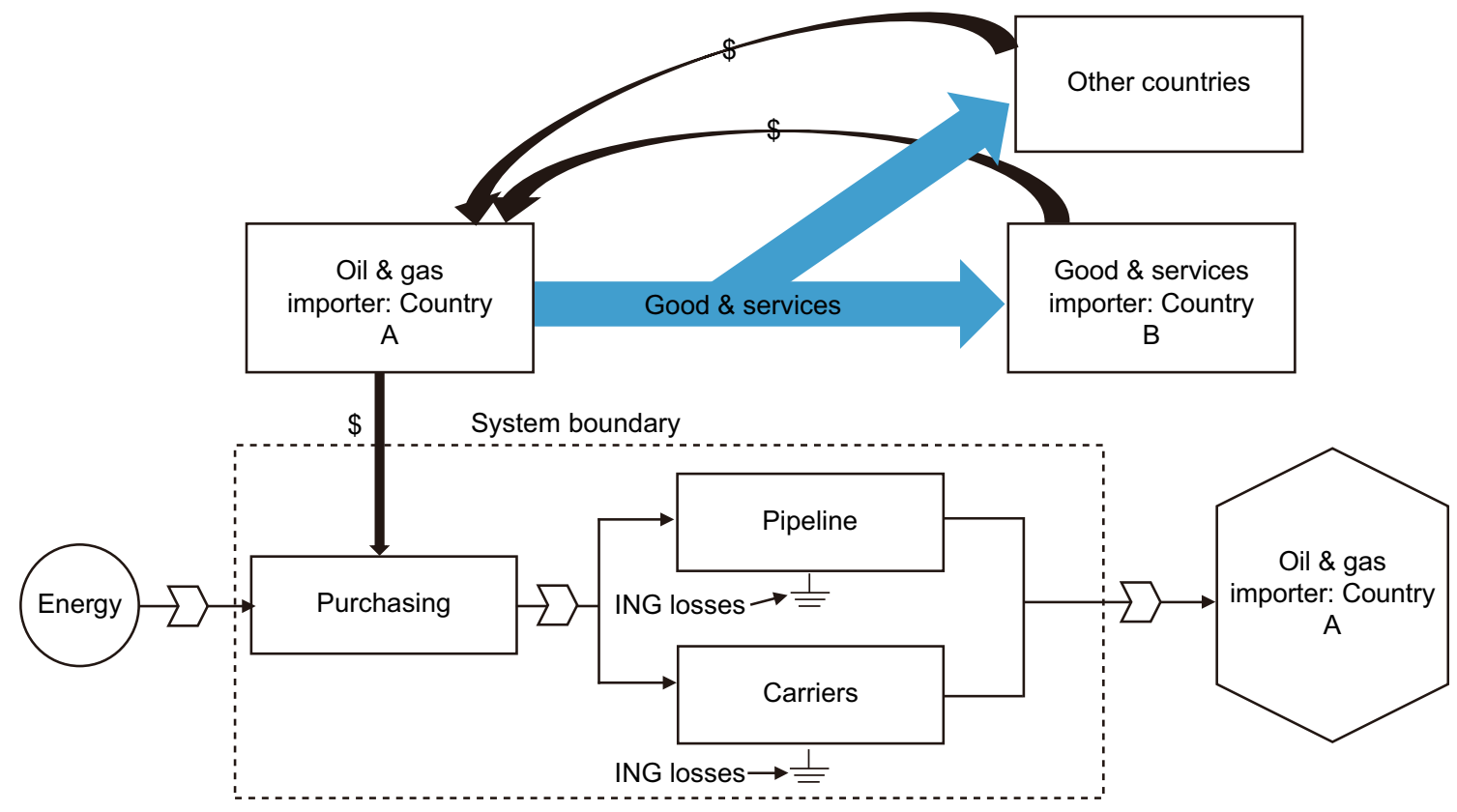

Fig. 3 System boundaries of IO and ING

where $E_{\mathrm{ING}}$ is the total energy content of the gas purchased, and $E_{\mathrm{p}, \mathrm{NG}}$ and $E_{\mathrm{t}, \mathrm{NG}}$ refer to the total energy inputs in the purchasing phase (equal to the energy required to make the goods exported to pay for the gas) and the international transportation phase, respectively. Unlike coal and oil, which remain almost unchanged after long distance transportation, gas may suffer some losses in transportation (Lin et al. 2010). Therefore, gas losses in transportation will be estimated and excluded from the total energy outputs. The EROI $_{\text {ING }}$ can be calculated with Eq. (7).

$\mathrm{EROI}_{\mathrm{ING}}=\frac{E_{\mathrm{ING}}-L_{\mathrm{t}, \mathrm{NG}}}{E_{\mathrm{p}, \mathrm{NG}}+E_{\mathrm{t}, \mathrm{NG}}}$

where $L_{\mathrm{t}, \mathrm{NG}}$ refers to the gas losses in international transportation.
For gas transportation by pipeline, gas losses usually result from fugitive emissions and flaring. According to the Intergovernmental Panel on Climate Change, gas losses in pipeline transportation can be calculated as follows (Zhang et al. 2013):

$L_{\mathrm{t}}=M_{\mathrm{t}} \times L R$

where $L_{\mathrm{t}}$ is the volume of gas losses, $\mathrm{kg} ; M_{\mathrm{t}}$ is the volume of gas transported, $\mathrm{m}^{3}$; and $L R$ is the loss rate caused by fugitive emissions and flaring, $\mathrm{kg} / \mathrm{m}^{3}$.

For gas transportation by tanker, gas losses result from boil-off gas (BOG) (Zakaria et al. 2013). Due to heat transfer from the surroundings to cryogenic LNG (liquefied natural gas), LNG is unavoidably vaporized, thus generating BOG in LNG tankers. To reduce the losses caused by 
BOG, some technologies are applied to re-liquefy the BOG at the expense of power consumption for liquefaction and the initial cost of the liquefying facilities (Lin et al. 2010). Here, we assume that the recovery rate of BOG is $r$, so $L_{\mathrm{t}}$ can be calculated using Eq. (9).

$L_{\mathrm{t}}=B(1-r)=M_{\mathrm{t}}\left[1-(1-B R)^{\frac{D_{\mathrm{t}}}{S \times 24}}\right](1-r)$

here $B$ is the BOG in transportation by LNG tankers, $\mathrm{m}^{3}$; $M_{\mathrm{t}}$ is the volume of gas transported, $\mathrm{m}^{3} ; B R$ is the boil-off rate, which refers to the percentage of LNG that needs to be boiled off to keep the LNG at the same temperature when heat is added to the LNG fuel ( $\times \% /$ day, e.g., $0.5 \% /$ day); $D_{\mathrm{t}}$ is the distance of international transportation, $\mathrm{km}$; and $S$ is the speed of the LNG tanker, $\mathrm{km} / \mathrm{h}$.

\subsection{Data for IO and ING}

\subsubsection{Energy content of oil and gas purchased}

The amounts of China's imported oil and gas (Table 15) are available from Wind Information Co., Ltd (Wind Info). Wind Info Import data cover the period from 1996 to 2015 (2015 data are only the sum of the first seven months). $E_{\mathrm{IO}}$ and $E_{\mathrm{ING}}$ (Table 16) are equal to these annual import volumes (Table 15) multiplied by the energy content factors in Table 3 .

\subsubsection{Energy inputs}

Energy investment in purchasing: The costs of purchasing oil and gas are from Wind Info (Table 15). The $E I_{\mathrm{GDP}}$ (in 2010 constant prices) in Fig. 4 is from National Bureau of Statistics of China (2014) and The People's Bank of China (2014). $E I_{\mathrm{GDP}}$ is multiplied by the cost of purchasing oil (gas) to create a time series of $E_{\mathrm{p}, \mathrm{OIL}}\left(E_{\mathrm{p}, \mathrm{NG}}\right)$ (Table 16$)$.

Energy investment in international transportation: The oil imported by tanker and by pipeline and the gas imported by tanker and by pipeline are shown in Fig. 5. Table 12 presents all of the data on the energy intensity and the fuel mix for each transportation mode. We assume that the transport distances for pipelines and tankers are 2000 and $8000 \mathrm{~km}$, respectively. Thus, the $E_{\mathrm{p}, \mathrm{OIL}}$ and $E_{\mathrm{p}, \mathrm{NG}}$ in Table 16 can be calculated; these values are equal to the transport distance multiplied by the traffic intensity and then multiplied by the transport volume.

\subsubsection{Gas losses in international transportation}

The values for transport volume by pipeline and by LNG tanker are shown in Fig. 5. Zhang et al. (2013) found that the loss rate $(L R)$ is $0.607 \times 10^{-3} \mathrm{~kg} / \mathrm{m}^{3}$. The volume of gas losses $\left(L_{\mathrm{t}}\right)$ for pipeline transport can be calculated using
Eq. (8). In this paper, we set the distance for LNG transport at $8000 \mathrm{~km}$. According to Lin et al. (2010), for large LNG carriers, the boil-off rate $(B R)$ is usually between $0.05 \% /$ day and $0.1 \% /$ day, where the middle value is $0.075 \% /$ day. Chu (2000) collected data on approximately 108 LNG ships and found the operating speed to be concentrated within the range of $32.4-37 \mathrm{~km} / \mathrm{h}$. The average speed is $34.7 \mathrm{~km} / \mathrm{h}$, which is the speed used in this paper. Assuming that the recovery rate of BOG $(r)$ is 0.7 , the volume of gas losses $\left(L_{\mathrm{t}}\right)$ for tanker transport can be calculated using Eq. (9). The $L_{\mathrm{t}, \mathrm{NG}}$ (Table 16) is the sum of the $L_{\mathrm{t}}$ for pipeline transport and the $L_{\mathrm{t}}$ for tanker transport.

\section{Results}

\subsection{EROI for China's oil and gas extraction}

The EROI ${ }_{\text {stnd }}$ for China varies from about 8.4:1 to 17.3:1, decreasing from 1985 to 2003 and then increasing again (Fig. 6). Obviously, with the depletion of oil reserves, production becomes more costly. In addition, the growth in energy consumption in turn leads to a decrease in the EROI, which is entirely consistent with the fact that until 2003, China's EROI was continually declining. However,

Table 15 Amounts and costs of IO and ING

\begin{tabular}{|c|c|c|c|c|}
\hline \multirow[t]{2}{*}{ Year } & \multicolumn{2}{|c|}{ The amounts $\left(10^{8}, \mathrm{~kg}\right)$} & \multicolumn{2}{|c|}{ The costs $\left(10^{8}\right.$, dollars $)$} \\
\hline & $\mathrm{IO}$ & ING & IO & ING \\
\hline 1996 & 155 & & 21 & \\
\hline 1997 & 340 & & 53 & \\
\hline 1998 & 274 & & 33 & \\
\hline 1999 & 328 & & 53 & \\
\hline 2000 & 640 & & 135 & \\
\hline 2001 & 558 & & 108 & \\
\hline 2002 & 634 & & 116 & \\
\hline 2003 & 865 & & 188 & \\
\hline 2004 & 1141 & & 315 & \\
\hline 2005 & 1232 & & 464 & \\
\hline 2006 & 1385 & & 634 & \\
\hline 2007 & 1534 & & 750 & \\
\hline 2008 & 1733 & & 1247 & \\
\hline 2009 & 1952 & 55 & 850 & 13 \\
\hline 2010 & 2309 & 119 & 1302 & 40 \\
\hline 2011 & 2464 & 226 & 1904 & 104 \\
\hline 2012 & 2635 & 305 & 2142 & 168 \\
\hline 2013 & 2732 & 378 & 2128 & 204 \\
\hline 2014 & 2864 & 404 & 2122 & 225 \\
\hline 2015 & 1759 & 226 & 754 & 101 \\
\hline
\end{tabular}


Table 16 Energy outputs and inputs for IO and ING

\begin{tabular}{rrrrcrrr}
\hline Year & \multicolumn{1}{l}{$E_{\mathrm{IO}}$} & $E_{\mathrm{p}, \mathrm{OIL}}$ & $E_{\mathrm{t}, \mathrm{OIL}}$ & $E_{\mathrm{ING}}$ & $L_{t, \mathrm{NG}}$ & $E_{\mathrm{p}, \mathrm{NG}}$ & $E_{\mathrm{t}, \mathrm{NG}}$ \\
\hline 1996 & 6479 & 569 & 28 & & & & \\
1997 & 14,212 & 1317 & 62 & & & & \\
1998 & 11,453 & 761 & 49 & & & & \\
1999 & 13,710 & 1172 & 59 & & & & \\
2000 & 26,752 & 2851 & 114 & & & & \\
2001 & 23,324 & 2176 & 99 & & & & \\
2002 & 26,501 & 2272 & 110 & & & & \\
2003 & 36,157 & 3857 & 148 & & & & \\
2004 & 47,694 & 6818 & 189 & & & & \\
2005 & 51,498 & 9877 & 202 & & & & \\
2006 & 57,893 & 12,774 & 222 & & & & \\
2007 & 64,121 & 13,695 & 247 & & & & \\
2008 & 72,439 & 19,710 & 288 & & & & \\
2009 & 81,594 & 12,730 & 321 & 3163 & 9 & 189 & 10 \\
2010 & 96,516 & 18,541 & 379 & 6833 & 16 & 571 & 37 \\
2011 & 102,995 & 25,366 & 398 & 12,908 & 24 & 1387 & 100 \\
2012 & 110,143 & 26,876 & 422 & 17,432 & 31 & 2107 & 145 \\
2013 & 114,198 & 25,710 & 437 & 21,631 & 38 & 2463 & 181 \\
2014 & 119,715 & 25,381 & 458 & 23,113 & 41 & 2689 & 189 \\
2015 & 73,526 & 8800 & 282 & 12,944 & 22 & 1180 & 112 \\
\hline & & & & & & &
\end{tabular}

after 2003, the EROI increased from 8.4:1 to 12.2:1. This increase is mainly a result of the increasing EROI for gas extraction. Another factor is that energy savings programs in the industry have been implemented.

\subsection{The EROI for oil and gas companies}

As shown in Table 17, the EROI ${ }_{\text {stnd }}$ for CNPC increased significantly from $9.5: 1$ in 2001 to $11.1: 1$ in 2013. This increase in $\mathrm{EROI}_{\mathrm{stnd}}$ is attributed to the fact that CNPC has made great effort to develop natural gas, which has a higher EROI than oil. From 2001 to 2013, natural gas production has increased from $825 \times 10^{9}$ to $4042 \times 10^{9}$ MJ, which is an average annual increase in $14.2 \%$. Meanwhile, in the development of natural gas, in 2012, the OGE of the CNPC Changqing Oilfield reached $1800 \times 10^{9}$ $\mathrm{MJ}$ (for the first time it produced more oil and gas than the CNPC Daqing Oilfield), making it the largest oil and gas field in China. Moreover, CNPC vigorously developed energy-saving technologies to improve its energy efficiency, which in turn helped to improve its EROI.

For Sinopec's OGE, since 2009, the EROI increased from 9.9:1 in 2009 to 10.6:1 in 2013 (Table 17). The EROI $_{2, \mathrm{~d}}$ increased from 6.1:1 in 2006 to $6.9: 1$ in 2010 and remained unchanged at approximately $6.7: 1$ between 2010 and 2013 (Table 18). Because the information is limited in the public domain, it is impossible to explain accurately all of the above phenomena in this paper. However, we can see that one reason is that the potential for energy savings was being exhausted, as shown in Fig. 7 (CNPC Annual Reports; Sinopec Annual Reports; CNOOC Annual Reports; Yanchang Social Responsibility Reports).

CNOOC's EROI ${ }_{\mathrm{OGE}}$ is higher than that of CNPC, Sinopec, and Yanchang. The main reason may be that compared with onshore oil fields, the degree of development of offshore oil resources is relatively low, and the production cost is relatively cheap. There are two reasons for the low degree of exploration: On the one hand, offshore oil resource development takes longer time than onshore oil development; on the other hand, at present, only CNOOC is engaged in offshore oil exploration and development, whereas CNPC and Sinopec, the two largest oil companies in China, are engaged mainly in onshore oil exploration and development. Currently, because of the lack of data, we cannot provide an answer as to why the CNOOC's EROI ${ }_{\text {OGE }}$ between 2005 and 2008 has been slightly fluctuating near approximately 10.9:1. To provide an explanation, we need more detailed data on energy consumption. In terms of refining, in 2009, CNOOC's 12 Mt/a Huizhou Refinery Project Phase I was completed and put into production, marking the CNOOC entrance into the refining business (CNOOC Annual Reports). The Huizhou Refinery Project is a large-scale refinery in China that is especially designed to process high acid heavy crude oil, which requires more energy consumption and has a lower light oil extraction rate, resulting in a lower EROI. As shown in Table 18, the $\mathrm{EROI}_{2, \mathrm{~d}}$ for CNOOC is significantly lower than that of the other companies in 2009.

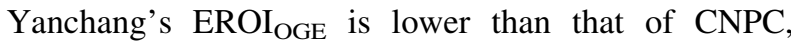
Sinopec, and CNOOC (Table 17), because the Yanchang has been producing oil from depleted fields. In 1905, the Yanchang Petroleum Factory was established, and in 1907, Yanchang drilled the first oil well in mainland China (Zuo 2009). As shown in Fig. 8, the growth rate of crude oil production of Yanchang declines with time; in 2013, it fell $0.1 \%$ compared with that in 2012. However, the energy efficiency of OGE for Yanchang has a trend of slight increase, although the Yanchang's EROI is lower than that of the other companies. This may be attributed to the increased natural gas production and energy efficiency measures. In 2010, Yanchang began to produce natural gas, and the production of natural gas increased from $0.4 \times 10^{9}$ in 2010 to $18 \times 10^{9} \mathrm{MJ}$ in 2013 (Fig. 8). In terms of energy efficiency, Yanchang formulated the "Environmental Governance Programme 2011-2013," in which energy conservation was considered an important environmental protection measure. Yanchang's energy savings in 2013 was $2 \times 10^{9} \mathrm{MJ}$, which was slightly higher than in 2011 (Fig. 8) (Yanchang Social Responsibility Reports). 


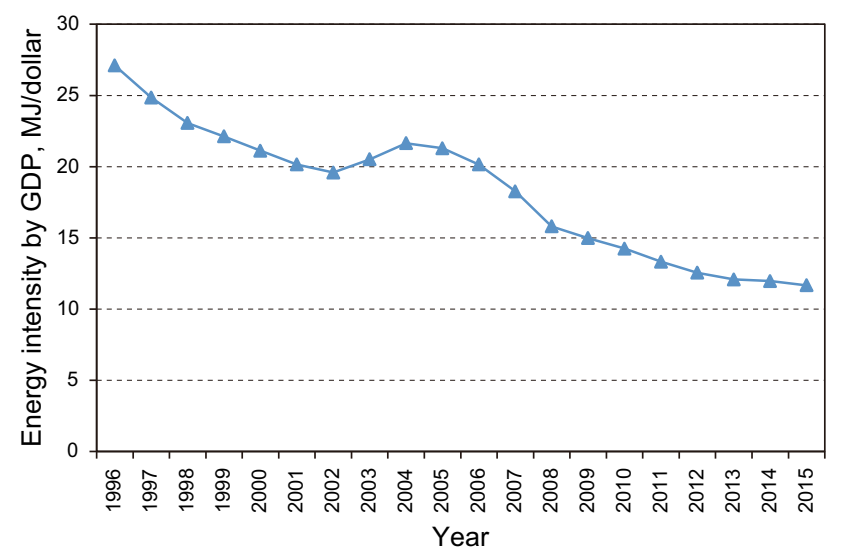

Fig. 4 Energy intensity of GDP

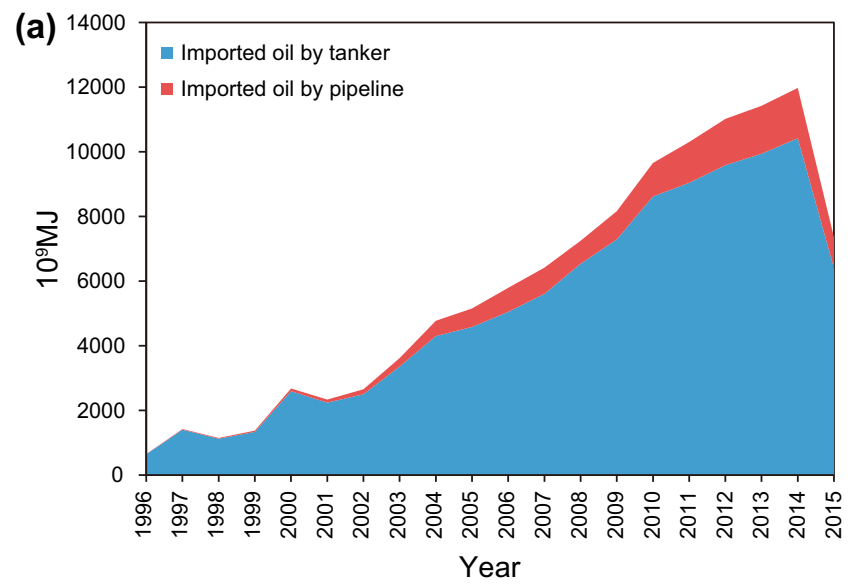

\subsection{The EROI for imported oil and imported natural gas}

The EROI ${ }_{\mathrm{IO}}$ and $\mathrm{EROI}_{\mathrm{ING}}$ are calculated based on Eqs. (5)

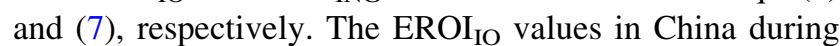
"good times" (i.e., the late 1990s) and "bad times" (i.e., 2006-2008) are shown in Fig. 9. The EROI IO shows a peak of approximately 14.8 in 1998 and a value of approximately 8.4 in 2015 ; overall, the figure presents a fluctuating but declining trend over the entire study period (slope of $\left.-0.44, R^{2}=0.6\right)$ reflecting increasing relative prices of petroleum. The patterns in the EROI values for IO and ING have broadly similar trends during the period from 2009 to 2015. From 2009 to 2012, they show a sharp and sustained decline. From 2012 to 2014, they remained relatively

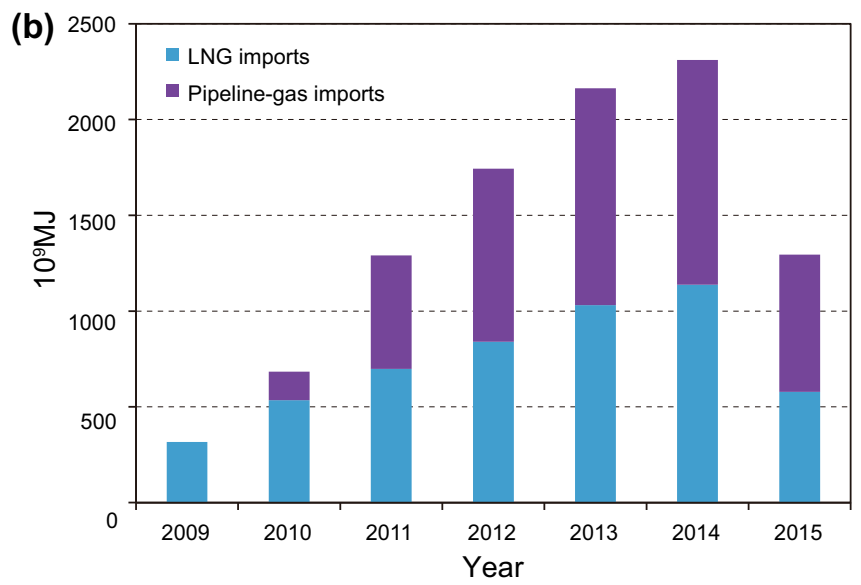

Fig. 5 Amounts of IO and ING by tanker and by pipeline (NB. 2015 data are only for 7 months)

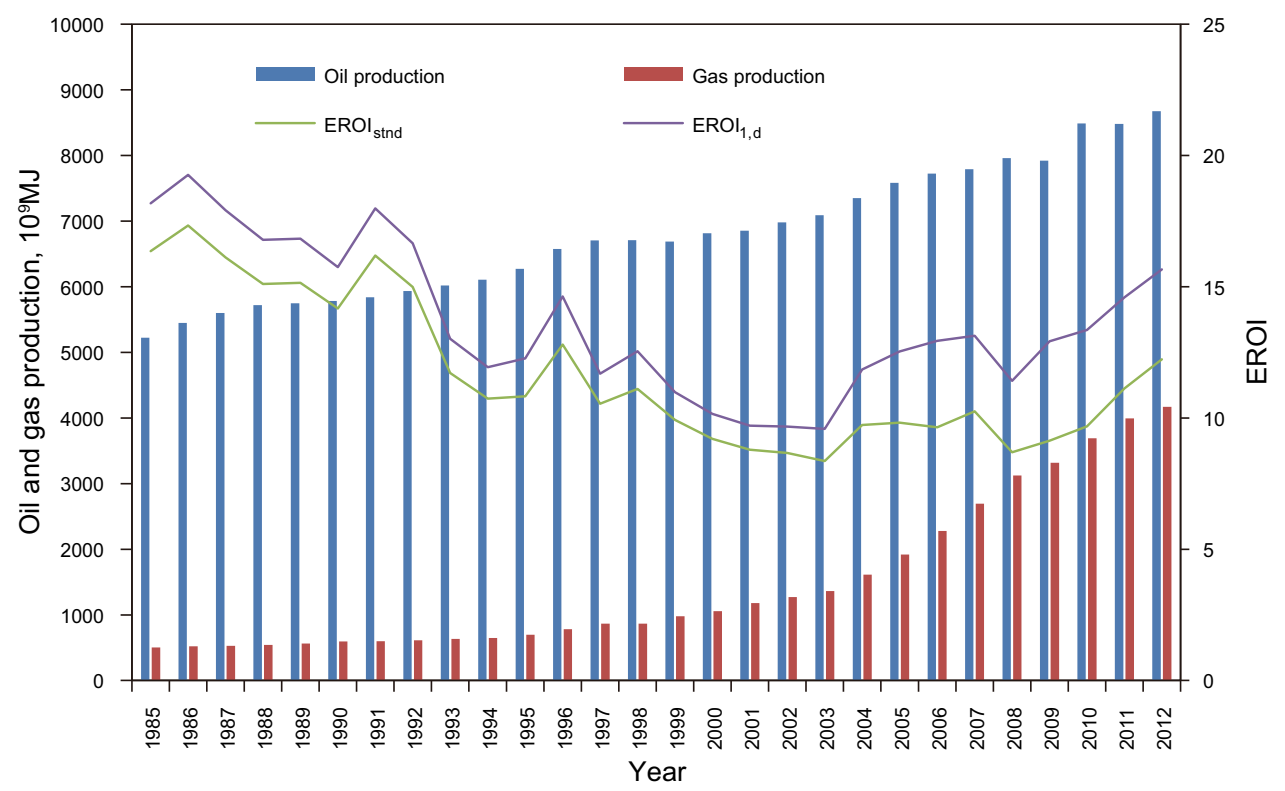

Fig. 6 EROI of China's OGE 
Table 17 EROI $_{\text {stnd }}$ of each company

Table 18 EROI $_{2, \mathrm{~d}}$ of each company

\begin{tabular}{llllllrrrrrrrr}
\hline & 2001 & 2002 & 2003 & 2004 & 2005 & 2006 & 2007 & 2008 & 2009 & 2010 & 2011 & 2012 & 2013 \\
\hline CNPC & 9.5 & 9.6 & 9.2 & 9.0 & 8.6 & 8.7 & 9.0 & 8.7 & 8.4 & 9.1 & 10.0 & 10.5 & 11.1 \\
Sinopec & & & & & & 9.5 & 10.6 & 10.3 & 9.9 & 10.3 & 10.3 & 10.5 & 10.6 \\
CNOOC & & & & & 11.0 & 10.9 & 10.9 & 10.8 & 9.9 & & & & \\
Yanchang & & & & & & & & & & & 9.1 & 9.8 & 10.0 \\
\hline
\end{tabular}

\begin{tabular}{llllllllllllll}
\hline & 2001 & 2002 & 2003 & 2004 & 2005 & 2006 & 2007 & 2008 & 2009 & 2010 & 2011 & 2012 & 2013 \\
\hline CNPC & 4.9 & 4.9 & 5.0 & 5.2 & 5.2 & 5.4 & 5.5 & 5.6 & 5.9 & 6.1 & 6.3 & 6.4 & 6.6 \\
Sinopec & & & & & & 6.1 & 6.3 & 6.4 & 6.6 & 6.9 & 6.7 & 6.7 & 6.7 \\
CNOOC & & & & & & & & & 3.5 & & & & \\
Yanchang & & & & & & & & & & & 4.6 & 5.0 & 5.1 \\
\hline
\end{tabular}

stable. In 2015, they began to increase as oil prices again decreased relative to exported commodities.

\section{Discussion}

\subsection{Comparison with previous estimates for China's oil and gas}

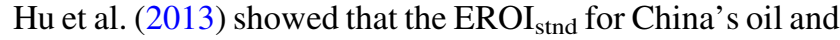
gas extraction fluctuated from 12 to $14: 1$ in the mid-1990s and declined to $10: 1$ in the period from 2007 to 2010 (Fig. 10). The EROI $\mathrm{I}_{\text {stnd }}$ trends documented in this paper are

Fig. 7 Amount of energy savings for China's oil companies

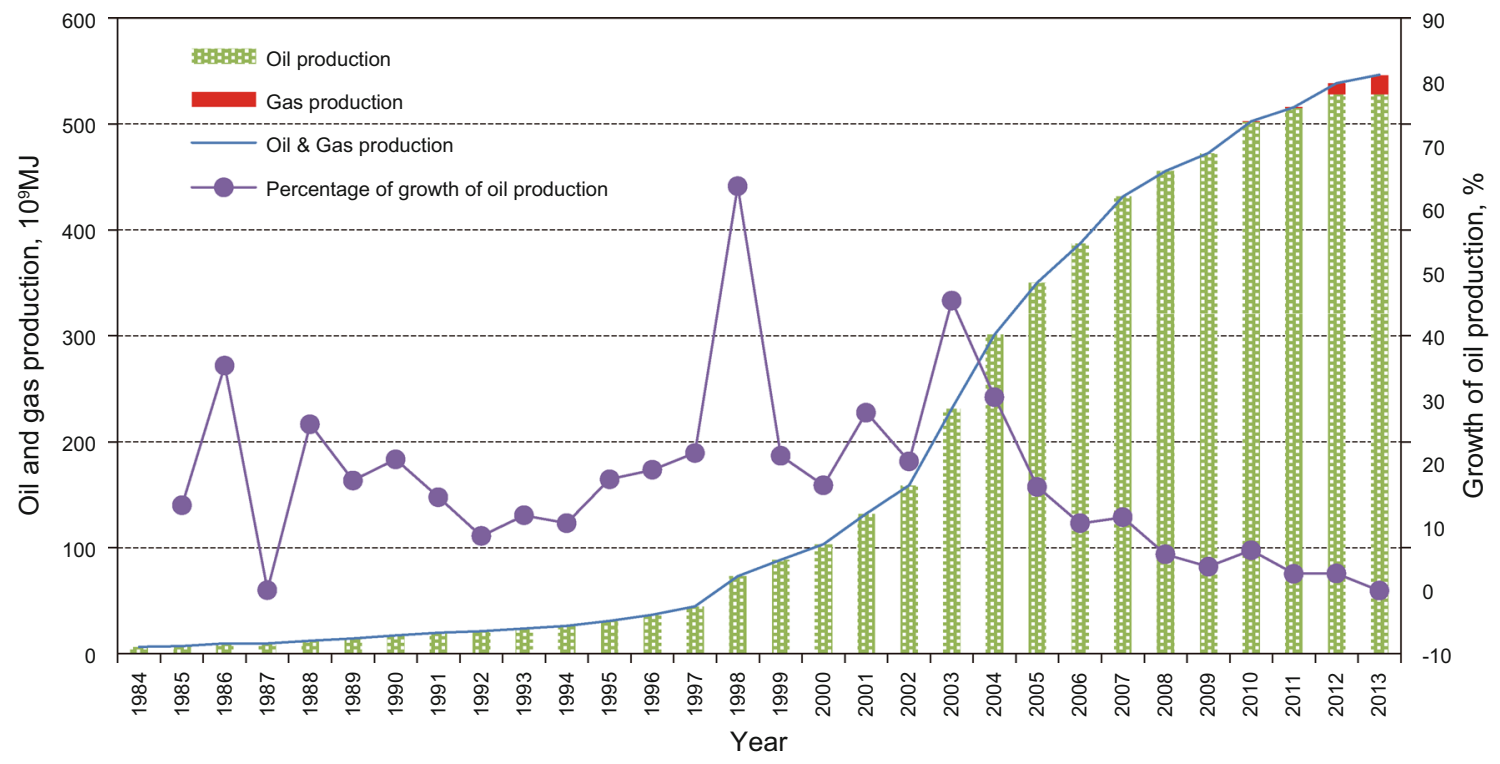

Fig. 8 OGE of Yanchang 


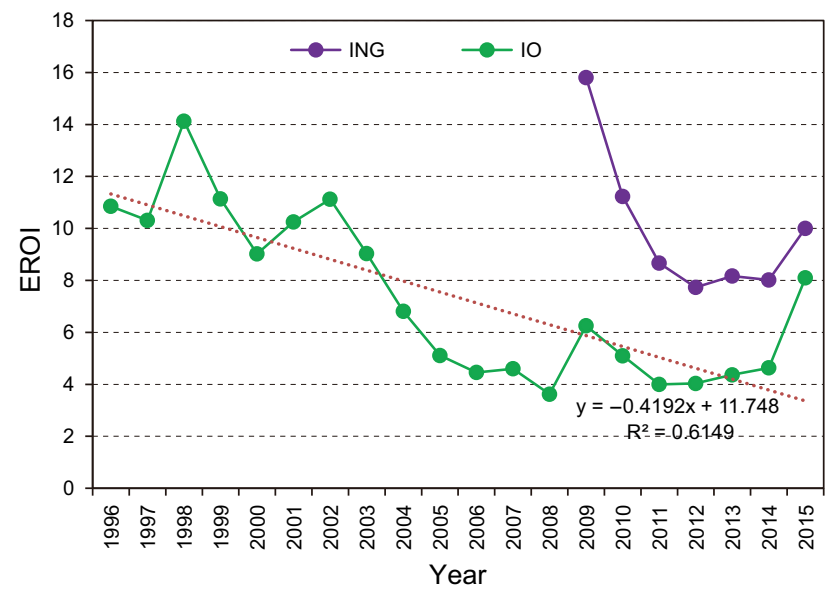

Fig. 9 EROI $_{\mathrm{IO}}$ and $\mathrm{EROI}_{\mathrm{ING}}$ in China

similar to those of Hu et al. (2013) with the only difference being that the EROIs in this paper are somewhat lower than theirs, which results from that their study considering only 8 main fuels (natural gas, crude oil, electricity, diesel oil, raw coal, fuel oil, gasoline, and refinery gas), and ignoring some fuels that are used in small amounts such as liquefied petroleum gas, while this paper considers them. The discrepancy between $\mathrm{EROI}_{1, \mathrm{~d}}$ and EROI $\mathrm{Etnd}_{\text {stn }}$ has been increasing, which suggests that indirect energy inputs are increasing.
$\mathrm{Hu}$ et al. (2011) estimated that the EROI of CNPC's Daqing Oilfield, China's largest, declined continuously from 10:1 in 2001 to $6: 1$ in 2009. From Fig. 10, we can find that the EROI of the Daqing Oilfield is lower than that of CNPC overall, and the discrepancy continues to increase. There are two reasons for this result. The principal reason is that as Daqing's fields age, they require more energy-intensive techniques, such as high pressure water and polymer injections. The discovery of the Daqing oil field in 1959 made China an oil-rich country (Hu et al. 2011). After 40 years of development, its oil production began to decline in 1998. The production of the Daqing oil field has been decreasing from its peak of $2328 \times 10^{9}$ to $1672 \times 10^{9} \mathrm{MJ}$ in 2013. During this period, oil production was maintained, and the water content was mainly controlled by increasing the water pressure beneath the oil and using polymer flooding technology, thus leading to an increase in energy inputs. Daqing's natural gas production in 2013 was $134 \times 10^{9} \mathrm{MJ}$, and compared with 1998 , it only increased by $43 \times 10^{9} \mathrm{MJ}$. The other reason is that other CNPC oil fields produced more oil and gas. Of these fields, the most noteworthy is the Changqing Oilfield. Over the period from 1998 to 2013, its oil and gas production increased by 12 per cent and 31 per cent annually, respectively, reaching $1017 \times 10^{9}$ and $1349 \times 10^{9}$ MJ (Fig. 11) (Wang 2004a, b; Zhao and Xiao 2009a, b; Xiao 2014a, b).

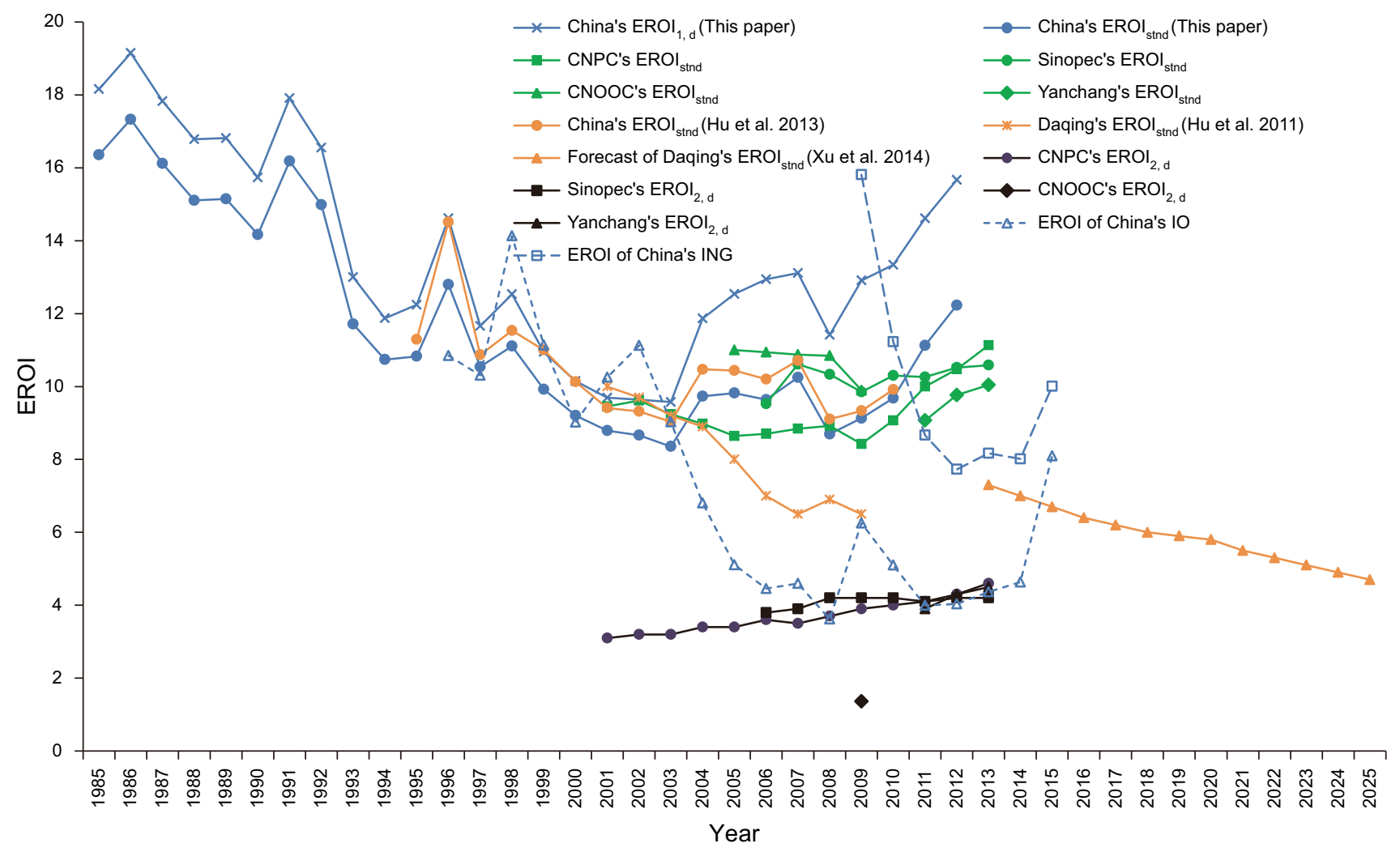

Fig. 10 Comparison with previous estimates of China's oil and gas 

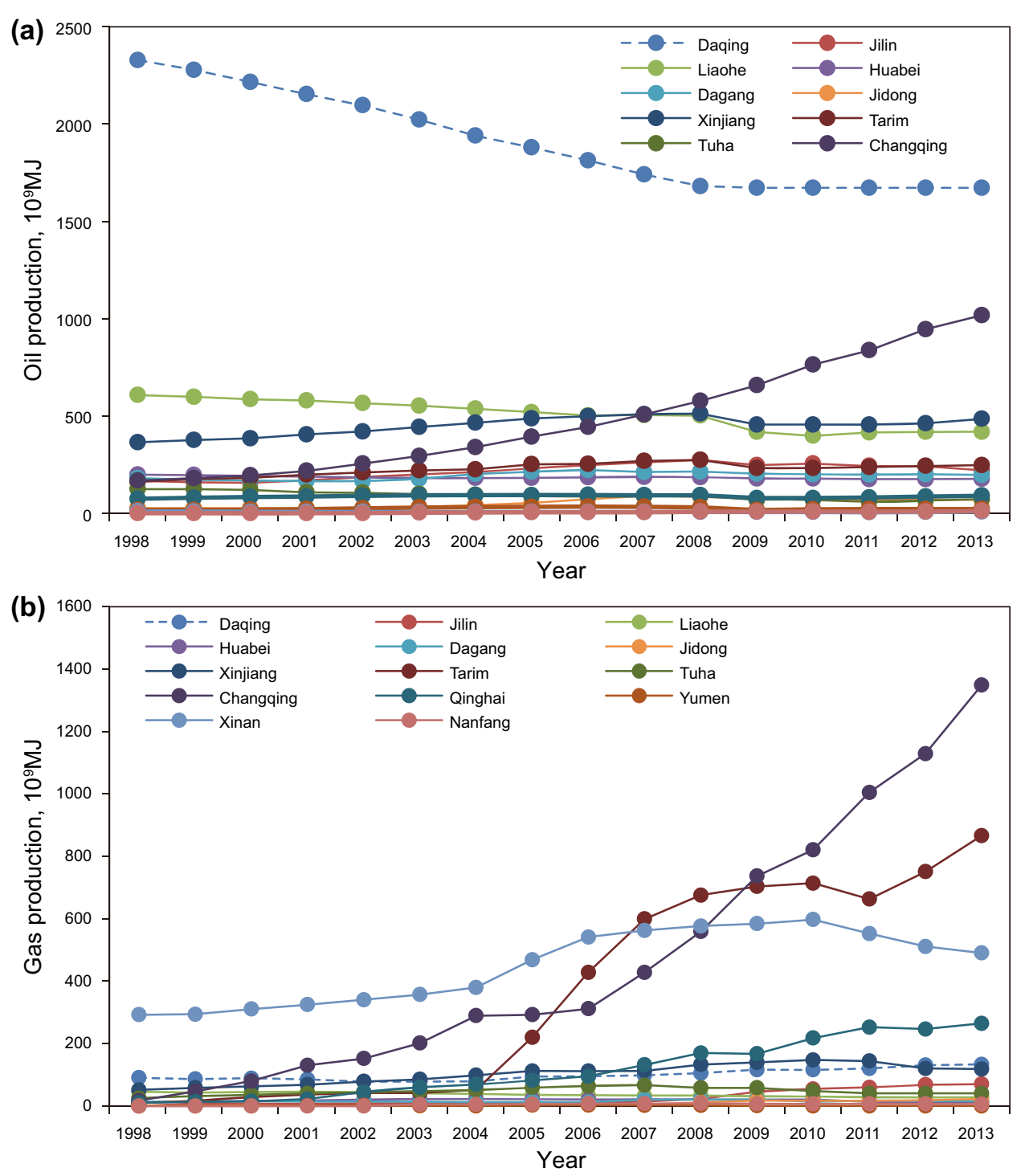

Fig. 11 Oil (left) and gas (right) production of CNPC's oilfields

Our EROI estimates for IO fall within the range of previously published studies. Lambert et al. (2014) provided an EROI analysis for IO for 12 developing countries, including China. The authors found that most developing nations had EROI $_{\text {IO }}$ values below 8-10, which are very similar to our results. They also found that there were two EROI IO peaks for oil imported into China. One peak occurred in 1998, which is the same as our results. Until now, no studies have estimated the EROI ${ }_{\text {ING. }}$. Our study shows that the EROI ING has also shown a declining trend, similar to the $\mathrm{EROI}_{\mathrm{IO}}$.

\subsection{Policy implications}

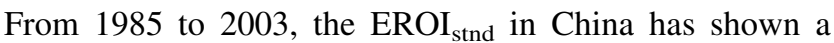
declining trend, while after 2003, the EROI ${ }_{\text {stnd }}$ started to increase due the development of NG, which may have a better energy return. Therefore, the government should take measures to increase gas production. We believe that the most significant measure would be to rationalize the domestic NG pricing mechanisms, which would improve the enthusiasm of enterprises to develop NG. Since the 1990s, the Chinese government has implemented several NG price reforms. The pricing method for NG has evolved from government pricing to a two-track implementation to prices set with government guidance and finally to the current market net back value method (Kong et al. 2015). Although the pricing mechanisms have gradually improved, market-oriented pricing is still not used for China's NG.

In Sect. 5.1, by comparison with EROI ${ }_{\text {stnd }}$ and $\mathrm{EROI}_{1, \mathrm{~d}}$, we found that indirect energy inputs have a significant and negative impact on China's EROI. Therefore, to improve the EROI, indirect energy inputs should be controlled. Using the "purchase of equipment and instruments" as an 
example, on the one hand, oil companies should reduce their amount of equipment and instruments by improving their utilization. On the other hand, equipment manufacturing enterprises should improve their energy efficiency, thereby reducing energy consumption in the equipment production process.

The EROI ${ }_{I O}$ and EROI ING are both continually decreasing. If import prices continue to increase, and hence, the EROI $\mathrm{IO}_{\mathrm{O}}$ declines, the result will likely correspond to lower quality of life indices for China's citizens (Lambert et al. 2014). Therefore, the question that must be asked is, "What opportunities does China have to mitigate the effects of these rising energy prices and the declining EROI of its imported fuel?" Improving the efficiency at which China's economy converts energy and material into marketable goods, and services is one means of improving the country's energy security (Lambert et al. 2014). The other method is to support moderate EROI renewable energy production, which might serve to improve China's net energy balance based on a poor EROI for imported oil and gas through trade.

China is experiencing an EROI decline, which is a risk of unsustainable fossil resource use. Therefore, China must be able to foresee, understand, and plan for changes in its broad energy landscape, particularly during what researchers have characterized as post-peak oil production. Furthermore, sustainability could be effectively addressed by the emergence of a new field: Transition Engineering, which is a new approach to engineering to address the risks of unsustainability so that a vision of a desirable future can be identified and delivered (Transition Engineering). It addresses three key engineering challenges:

Climate: re-engineering systems so they do not cause and are resilient to climate change.

Peak oil: re-engineering systems so they do not depend on fuel; e.g., using $90 \%$ less fuel.

EROI: re-engineering systems so they only use energy with high EROI; e.g., on the order of $>10$.

Meeting these three challenges could be the way that Chinese society reduces both fossil fuel use and the detrimental social and environmental impacts of industrialization (Krumdieck 2013). Although it is still in its infancy, Transition Engineering should be investigated as a direction for future research by governments, scholars, scientists, and even ordinary people.

\section{Conclusion}

In this paper, we calculated the EROI for domestic production and imports of oil and gas in China. Our estimates show that the EROI ${ }_{\text {stnd }}$ in China decreased from approximately 17.3:1 in 1986 to $8.4: 1$ in 2003, and it increased to $12.2: 1$ in
2013. From a company-level perspective, the $\mathrm{EROI}_{\text {stnd }}$ differs for different companies and was in the range of 8-12:1. Compared with the $\mathrm{EROI}_{\text {stnd }}$, the $\mathrm{EROI}_{2, \mathrm{~d}}$ declined by $50 \%$ $80 \%$ and was in the range of 3-7:1. The EROI ${ }_{\mathrm{IO}}$ declined from 14.8:1 in 1998 to approximately 4.8:1 in 2014, and the EROI $_{\text {ING }}$ declined from 16.7:1 to 8.6:1 from 2009 to 2014. In 2015 , the $\mathrm{EROI}_{\mathrm{IO}}$ and $\mathrm{EROI}_{\mathrm{ING}}$ have shown a slight increase due to decreasing oil and gas prices. In general, this paper suggests that from a net energy perspective, it will become more difficult for China to obtain oil and gas from both domestic production and imports.

Acknowledgments We gratefully acknowledge that this work is supported by the National Natural Science Foundation of China (No. 71273277) and the Philosophy and Social Sciences Major Research Project of the Ministry of Education (No. 11JZD048).

Open Access This article is distributed under the terms of the Creative Commons Attribution 4.0 International License (http://crea tivecommons.org/licenses/by/4.0/), which permits unrestricted use, distribution, and reproduction in any medium, provided you give appropriate credit to the original author(s) and the source, provide a link to the Creative Commons license, and indicate if changes were made.

\section{References}

BP Statistical Review of World Energy. 2014. http://www.bp.com/en/ global/corporate/about-bp/energy-economics/statistical-reviewof-world-energy.html. Accessed 10 Jan 2015.

Brandt AR, Englander J, Bharadwaj S. The energy efficiency of oil sands extraction: energy return ratios from 1970 to 2010 . Energy. 2013;55:693-702.

Cleveland C. Net energy from the extraction of oil and gas in the United States. Energy. 2005;30:769-82.

Cleveland CJ, O'Connor PA. Energy return on investment (EROI) of oil shale. Sustainability. 2011;3:2307-22.

CNOOC Annual Reports. http://www.cnooc.com.cn/col/col1921/ index.html. Accessed 21 Jan 2016.

CNPC Annual Reports. http://www.cnpc.com.cn/cnpc/ndbg/gywm list.shtml. Accessed 25 July 2016.

Chu LY. Ship Type Evaluation for LNG import transportation of China. Master's thesis. Dalian Maritime University, Dalian, China. 2000 (in Chinese).

Fan J, Wang Q, Sun W. The failure of China's Energy Development Strategy 2050 and its impact on carbon emissions. Renew Sustain Energy Rev. 2015;49:1160-70.

Gagnon N, Hall CAS, Brinker L. A preliminary investigation of energy return on energy investment for global oil and gas production. Energies. 2009;2:490-503.

Gong CB, Wang TY. Analysis of energy consumption of refineries and energy-saving optimization practice. Sino Glob Energy. 2013;18:90-4 (in Chinese).

Heun MK, Wit DM. Energy return on (energy) invested (EROI), oil prices, and energy transitions. Energy Policy. 2012;40:147-58.

$\mathrm{Hu}$ Y, Hall CAS, Wang J, et al. Energy return on investment (EROI) of China's conventional fossil fuels: historical and future trends. Energy. 2013;54:352-64.

$\mathrm{Hu}$ Y, Feng L, Hall CAS, et al. Analysis of the energy return on investment (EROI) of the huge Daqing oil field in China. Sustainability. 2011;3:2323-38. 
Hall CAS, Balogh S, Murphy DJR. What is the minimum EROI that a sustainable society must have? Energies. 2009;2:25-47.

Kong Z, Dong X, Zhou Z. Seasonal imbalances in natural gas imports in major northeast Asian countries: variations, reasons, outlooks and countermeasures. Sustainability. 2015;7:1690-711.

Kesicki F. The third oil price surge-what's different this time? Energy Policy. 2010;38:1596-606.

King CW. Energy intensity ratios as net energy measures of United States energy production and expenditures. Environ Res Lett. 2010;5:1-10.

Kaufmann R. In energy and resource quality: the ecology of the economic process. New York: Wiley; 1986.

Krumdieck S. Transition engineering: adaptation of complex systems for survival. Int J Sustain Dev. 2013;16:310-21.

Lundin J. EROI of crystalline silicon photovoltaics-variations under different assumptions regarding manufacturing energy inputs and energy output. 2013. http://uu.diva-portal.org/smash/record. jsf?pid=diva2\%3A620665\&dswid=-3486. Accessed 2 Oct 2014.

Lin W, Zhang N, Gu A. LNG (liquefied natural gas): a necessary part in China's future energy infrastructure. Energy. 2010;35:4383-91.

Lambert JG, Hall CAS, Balogh S, et al. Energy, EROI and quality of life. Energy Policy. 2014;64:153-67.

Murphy DJ, Hall CAS, Dale M, et al. Order from chaos: a preliminary protocol for determining the EROI of fuels. Sustainability. 2011;3:1888-907.

Mulder K, Hagens JN. Energy return on investment: toward a consistent framework. J Hum Environ. 2008;37:74-9.

Munasinghe M. The sustainomics trans-disciplinary meta-framework for making development more sustainable. Int J Sustain Dev. 2002;5:125-82.

National Bureau of Statistics of China. China statistic yearbook 1989-2013. Beijing: China Statistics Press; 2014 (in Chinese).

Ou X, Yan XY, Zhang X. Life-cycle energy consumption and greenhouse gas emissions for electricity generation and supply in China. Appl Energy. 2011;88:289-97.

Safronov A, Sokolov A. Preliminary calculation of the EROI for the production of crude oil and light oil products in Russia. Sustainability. 2014;6:5801-19.
Sinopec Annual Reports. http://www.sinopecgroup.com/group/gsjs/ gsbg/. Accessed 20 Aug 2014.

The People's Bank of China. Chinese Exchange Rate. http://www. pbc.gov.cn/publish/english/963/index.html. Accessed 26 Dec 2014.

Transition Engineering. http://www.transitionnetwork.org/initiatives/ transition-engineering. Accessed 21 Jan 2016.

Wang XX. Natural gas production in China's oil and gas fields in 1998-2003. Int Pet Econ. 2004a;2:61 (in Chinese).

Wang XX. Crude oil production in China's oil and gas fields in 1998-2003. Int Pet Econ. 2004b;2:60 (in Chinese).

Wind Info (Wind Information Co., Ltd.). http://www.wind.com.cn/ En/Default.aspx. Accessed 21 Jan 2016.

$\mathrm{Xu} \mathrm{B}$, Feng L, Wei W, et al. A preliminary forecast of the production status of China's Daqing oil field from the perspective of EROI. Sustainability. 2014;6:8262-82.

Xiao L. China's natural gas production in 2008-2013. Int Pet Econ. 2014a;4:93 (in Chinese).

Xiao L. China's crude oil production in 2008-2013. Int Pet Econ. 2014b;4:92 (in Chinese).

Yanchang Social Responsibility Reports. http://www.sxycpc.com/ shzr.jsp?urltype $=$ tree. TreeTempUrl $\&$ wbtreeid $=1735$. Accessed 25 Aug 2014.

Zhang B, Chen GQ, Li JS, et al. Methane emissions of energy activities in China 1980-2007. Renew Sustain Energy Rev. 2013;29:11-21.

Zakaria MS, Osman K, Abdullah H. Greenhouse gas reduction by utilization of cold LNG boil-off gas. Procedia Eng. 2013;53:645-9.

Zuo XL. Oil exploration and production in northwest of China during the national government. Master's thesis. Tianjin Normal University. Tianjin, China. 2009 (in Chinese).

Zhao H, Xiao L. China's natural gas production in 2003-2008. Int Pet Econ. 2009a;6:65 (in Chinese).

Zhao H, Xiao L. China's crude oil production in 2003-2008. Int Pet Econ. 2009b;6:66 (in Chinese). 